\title{
Innovation capacity: A perspective on innovation capabilities of consulting engineering firms
}

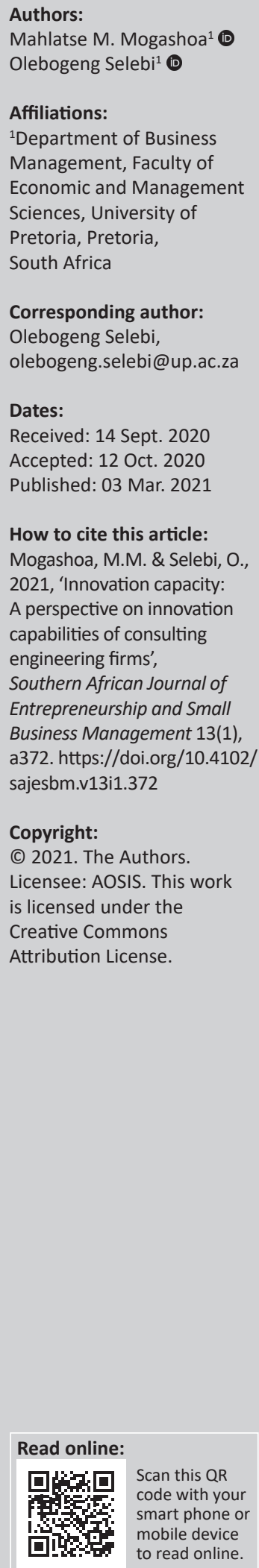

Background: Small and medium-sized enterprises (SMEs) play a significant role in job creation and bridging the widening gap between the rich and the poor in South Africa. Several factors determine the success of SMEs. One largely-overlooked factor is innovation capacity, which is made up of different capabilities.

Aim: The aim of this study is to investigate the degree of innovation capacity in South African consulting engineering firms and to identify the differences in the innovation capabilities across firm size.

Setting: The target population for the study was consulting engineering firms operating in South Africa.

Methods: The study followed a quantitative methodology. The survey was distributed using an email invitation to participate in the study, which contained a link to access the questionnaire online.

Results: The results show that South African engineering consulting firms reported an 'average' to 'high' innovation capacity, where medium and large-sized firms performed similarly, and small firms lagged. The study found that there exists a significant hierarchy in performance for entrepreneurial capabilities, risk management capabilities and capabilities for market and customer knowledge: larger firms reported a higher scoring than smaller firms. It also found that small firms sharply lagged behind medium and large-sized firms regarding risk management capabilities and capabilities for market and customer knowledge.

Conclusion: The results intend to assist policymakers in prioritising lagging capabilities as the point of departure for capability-building efforts. In addition, the results should assist entrepreneurs in being mindful of the potential blind spots that could be hindering growth.

Keywords: innovation; innovation capacity; innovation capability; small, medium and large-sized enterprises; consulting engineering firms; survey; South Africa.

\section{Introduction}

Since 2008, the construction industry has contributed approximately $9 \%$ to gross domestic product and 9\% to formal and informal employment in South Africa (Construction Industry Development Board 2015:2). However, ever since the Soccer World Cup projects in the year 2010, the construction industry has been in decline (PWC 2015:3). Despite small and medium-sized enterprises (SMEs) collectively being responsible for $56 \%$ of the turnover in the private sector construction industry during the December 2015 quarter, jobs are being shed in the same industry (Mhlanga 2016:45; Statistics South Africa 2016).

Small and medium-sized enterprises that grow have been considered as key contributors to job creation, poverty alleviation, equity and participation, wealth creation and social stability (Nieman \& Pretorius 2004:3; Olawale \& Garwe 2010:729). Consequently, these small, medium and micro-sized enterprises (SMMEs) have a considerable positive effect on South Africa's sustainable economic growth (Nieman \& Pretorius 2004:3; Olawale \& Garwe 2010:729). This positive impact stems from the fact that SMMEs increase stability within society, lead to a rise in personal savings, encourage prosperity in rural communities and increase the public's degree of economic participation (Cronje, du Toit \& Motlatla in Chimucheka 2013:784). All this is achieved whilst causing less damage to the environment compared to larger organisations (Cronje et al. in Chimucheka 2013:784). According to Baets (Cape Argus 2015), much of South Africa's hopes for job creation are pinned on SMMEs with the national development plan estimating that $90 \%$ of jobs would be created by this sector by 2030 . 
There exists a disconcertingly widening gap between South Africa's total early-stage entrepreneurial activity (TEA) and that of other sub-Saharan African countries (GEM 2014:22). South Africa's TEA remains low but has increased marginally each year over the last decade; however, from 2013 to 2014, South Africa's TEA dropped a staggering 34\% (GEM 2014:18). In addition, the level of business discontinuance in South Africa is still high in comparison to the number of business start-ups and surpasses the established business rate (GEM 2014:28). In essence, there is a net loss of small business activity in South Africa, and consequently, SMEs are unable to fulfil their developmental role in South Africa's sustainable economic growth (GEM 2014:28).

Statistics show that, on average, $71 \%$ of all South African SMMEs will be out of business by the fifth year of operation (Willemse 2010). In addition, 75\% of all new SMMEs in South Africa does not exist for more than 42 months; as a result, these SMEs do not become established enterprises (Olawale \& Garwe 2010:730). A developing nation like South Africa has many challenges such as an increasing unemployment rate, skills shortages, a high illiteracy rate, amongst others, and SMMEs should be empowered to contribute to solving these problems (Chimucheka 2013:783). More recent statistics show that the rate of established businesses in South Africa is as low as $2.2 \%$, which is a difference of only $0.9 \%$ from the lowest rate globally - Qatar reported the lowest rate of established business at 1.3\% (GEM 2018:37). Most of these enterprises cite a lack of finance and poor profitability as the key reason for business exit - this was cited in 2014, 2015, 2016 and 2017 (GEM 2014:4, 2018:37). The reasons for failure can be further attributed to a low entrepreneurial culture within the country, which manifests in low levels of businessrelated skills amongst South African entrepreneurs, inefficient and prohibitive support structures and infrastructure and entrepreneurs who are active in over-traded sectors that are populated with low-profit margin businesses within highly competitive and limited markets (GEM 2014:28).

Entrepreneurial SMEs have been identified as those ventures that contribute to employment and sustainable economic growth (Nieman \& Pretorius 2004:4). In recent years, more attention has been paid to the role of entrepreneurs in South Africa contributing substantially to economic growth and job creation (Chimucheka 2013:784). Entrepreneurial ventures are distinguished from small enterprises as being innovative, having the potential for growth and possessing strategic objectives within their business models (Ates \& Bititci 2011:5603; Nieman \& Pretorius 2004:6). Innovation is defined as creating, developing and adapting new ideas, processes or even products with the objective of amplifying the competitiveness of the enterprise. Innovation is therefore essential in a competitive environment. According to Chimucheka (2013:788), from a strategic standpoint, understanding competitors is key to SMMEs surviving the competitive business environment. Larger organisations are able to remain competitive by reducing prices, increasing their investment in advertising, improving product quality, etc. (Hellrigiel et al. in Chimucheka 2013:788). This increases rivalry, which may lead to a decline in industry profits and make the industry unattractive to investors and other stakeholders (David in Chimucheka 2013:788). Smaller businesses may not be able to compete in the same ways but can innovate to remain competitive. In addition to this, innovation is an essential tool for the 4th Industrial Revolution (4IR). According to Kruger and Steyn (2019:2), the introduction of 4IR has come with certain benefits for businesses that are able to make use of new-generation technologies, which are an important source of innovation. This is further emphasised by Schwab's (in Kruger \& Steyn 2019:3) statement that 'the scale and breadth of the unfolding technological revolution will usher in economic, social and cultural changes of such phenomenal proportions that they are almost impossible to envisage'. Innovation and 4IR go hand in hand. Fourth Industrial Revolution is important for entrepreneurs because it exposes them to technologies that, if correctly leveraged, can allow them to better compete in the marketplace (Kruger \& Steyn 2019:3). This would enable SMMEs to compete more effectively.

According to the Global Innovation Index (GII), South Africa's ranking went down from 54th in 2016 to 57th in 2017 and 58th in 2018 (Dutta, Lanvin \& Wunsch-Vincent 2016:281, 2017; Dutta et al. 2018:321). It is clear from the net loss of small business activity that developmental needs are considerable, and without locating the cause, the net loss may only be exacerbated (GEM 2014:29). Given the significance of the innovativeness of SMEs and the multiple studies that have been conducted on the innovativeness of large United States enterprises, or even small European enterprises and the like, there remains minimal available literature that has explored and measured the innovation capacity and innovation capabilities of South African SMEs particularly within the construction industry (Forsman 2011:739-750; Forsman \& Rantanen 2011; Gemünden \& Rohrbeck 2010). Innovation capacity is defined as the ability to take advantage of opportunities to better satisfy customer needs through the deployment of resources (Forsman 2011:740; Sok, O'Cass \& Miles 2015:2). These resources can be described as the supply of features owned by the enterprise, which contribute to the enterprise's competitive advantage (Forsman 2011:740; Park \& Ryu 2015:340). The innovation process takes place both internally and externally to the enterprise (Cantner, Conti \& Meder 2010:1939; Radas \& Božić 2009:439). The internal factor of a firm's innovation capacity is innovation capability which is based on absorptive capacity; the external factor is social capital (Forsman 2011:740; Vicente, Abrantes \& Teixeira 2015:30). Social capital theory considers the manner in which relationships develop for organisational benefit as well as the influence they have on decision-making (Toth 2006:514). In the quest for innovation, enterprises are immersed in networks of relationships with a miscellaneous range of competitors, agents, suppliers and research centres which assist the enterprise's innovation (Cantner et al. 2010:1939). 
The benefits of being in such networks are in the 'spillovers' of knowledge and technology (Cantner et al. 2010:1940). However, the internal process of absorptive capacity influences the degree to which these spillovers benefit the enterprise (Cantner et al. 2010:1940). Specific innovation capabilities drive the innovation capacity of an enterprise which, according to Forsman (2011:740), takes form through the internal and external factors of the innovation capacity. These capabilities are knowledge manipulation, collaboration, risk susceptibility, customer orientation, market knowledge and management capabilities, which are used to capitalise on opportunities and to apply the changes from spillovers (Forsman 2011:740).

It has been found that smaller firms do not necessarily have an innovation advantage but that the type of innovation depends on the dynamics of the industry and the economy in which it operates (Forsman 2011:741; Vicente et al. 2015:3). Consulting Engineers South Africa (CESA) defines SMEs based on only the total annual turnover. Consulting Engineers South Africa's definition of SMEs was adopted for the purpose of this study (Consulting Engineers South Africa [CESA] 2017):

- A small consulting engineering firm has an annual turnover equal to or less than R11.5 million.

- A medium consulting engineering firm's annual turnover exceeds R11.5m but not R35m.

- A large consulting engineering firm's annual turnover exceeds R35m.

This study is conducted to enhance the body of knowledge available to academics on the topic of innovation development within the construction industry. The findings are to assist practitioners in identifying discrepancies in innovation capabilities in order to bridge these discrepancies and build their firms' innovation capacity. The results would also be useful to the Sector Education and Training Authority's (SETA). Sector Education and Training Authority's 'primary function is to facilitate skills development by establishing learning programmes such as learnerships, skills programmes, internships and other strategic learning initiatives' (Services SETA 2020). Sector Education and Training Authorities are sector-specific and provide skills training to individuals who are employed or want to be employed in a specific sector (National Skills Authority [NSA] 2020). They are valuable in that they provide people with skills needed by industry (NSA 2020). The Construction Education and Training Authority (CETA) is the SETA that focuses on developing skills within the construction sector. Its mission 'is to create a solid skills base as a foundation for infrastructural development and economic empowerment' (National Government of South Africa 2020).

In addition, the results of the study will assist policymakers in identifying which innovation capabilities are lagging amongst consulting engineering firms within the construction industry and, therefore, require a more enabling environment.
The purpose of the study is to investigate the innovation capacity of small and medium-sized South African consulting engineering firms and to identify the differences in the innovation capabilities of these SMEs. The proposed study aims to answer the following research questions:

- What is the degree of innovation capacity of small, medium and large-sized South African consulting engineering firms?

- Are there significant differences in the innovation capabilities of small, medium and large-sized South African consulting engineering firms?

\section{Literature review Innovation capacity}

Innovation capacity is a broad concept that highlights both the internal and external aspects of an enterprise (Smith et al. 2011:9). The authors define innovation capacity as the propensity of an enterprise to spot new developments and technologies and to attain and capitalise on this knowledge and information. If one takes a standpoint from a resource perspective, innovation capacity is defined as the human and interpersonal efforts as well as the intermediate reframing of assets that facilitate an enterprise to participate in activities needed for innovation (Jørgensen \& Ulhøi 2010:399). Innovation is both a process ('how' to innovate) and an outcome ('what' to innovate) (Crossan \& Apaydin in Oura, Zilber \& Luiz Lopes 2015:924). According to Forsman (2011:740), innovation capacity is an enterprise's capability to progress its resources and capabilities to discover and take advantage of opportunities to better satisfy customer needs; thus, innovation capacity is driven by resources and different capabilities. For the purposes of this study, Forsman's (2011:740) definition was adopted because this conceptualisation incorporates an enterprise's internal and external aspects, and it describes innovation capacity as being necessary for the innovation process that satisfies customer needs. The literature has pointed out that innovation capacity differs from industry to industry, depending on the firm size (Enkel \& Heil 2014:244; Forsman 2011:741; Spithoven, Clarysse \& Knockaert 2011:13; Vicente et al. 2015:30). The stronger a firm's innovation capacity, the better the innovation process and performance (Kostopoulos et al. 2011:1335; Smith et al. 2011:8).

Smith et al. (2011:8) link human capital and technological capital as incentives that develop innovation capacity - of which learning plays a role in the innovation process. In emphasising innovation capacity, the 2014 GII focuses on human capital as a contributor to the increase in innovation capacity (Bernard et al. 2014:4). Bernard et al. (2014:6) describe human capital as the 'stock of knowledge or skills' of educated people. Bernard et al. (2014:6) further view education as a mechanism to hasten the technological process of an enterprise. An enterprise's innovation capacity increases through the acquisition of knowledge by the human capital of the enterprise, through the building of 
networks and through collaboration across borders in the form of social capital (Bernard et al. 2014:7). Social capital is an enterprise network which directly and indirectly provides the enterprise with knowledge for innovation (Cantner et al. 2010:1940). It investigates the social structures that are valuable to organisations and supports the actions of individuals and organisations that form part of it (Seibert, Kraimer \& Liden 2001:220).

Smith et al. (2011:24) further tie human capital with social capital through knowledge management in the form of collaboration, networks, knowledge sharing and learning.

To conclude, innovation capacity makes use of different capabilities of an enterprise to progress its resources and take advantage of the opportunities that better satisfy customer needs (Forsman 2011:740). Forsman (2011:740) observed research and development (R\&D) investment, innovation capabilities and external input to measure the degree of innovation capacity. However, for the purpose of this study, innovation capacity was measured by the degree of innovation capabilities alone. These capabilities are discussed in detail in the section 'Innovation capabilities'.

\section{Innovation capabilities}

The term capability brings to the surface many conceptual definitions. However, there is consensus on capability being a capacity for the deployment of resources (Forsman 2011:740; Sok et al. 2015:2). For this reason, capability is a subdimension that affects the overarching construct of innovation capacity (Forsman 2011:740; Sok et al. 2015:2). Sok et al.'s (2015:3) definition of capabilities goes on to describe them as 'bundles of interrelated processes and routines'. This statement, therefore, suggests that capabilities are embedded within the enterprise. This view is consistent with Vicente et al.'s (2015:30) view, which conceptualises capabilities as being entangled, multi-dimensional and embedded in organisational routines and practices. Innovation capabilities, therefore, describe the deployment of resources through embedded, multi-dimensional organisational practices, processes and routines - in so far as it transforms an enterprise's resources into the enterprise's innovation objectives (Forsman 2011:740).

Resources are conceptualised as being a supply of features owned by the enterprise and are, therefore, controlled by that enterprise (Forsman 2011:740). This definition concurs with Park and Ryu (2015:341), as well as Sok et al. (2015:3), who conceptualise resources as being controllable assets entrenched within the enterprise's culture and/or are protected by law through legal property rights. In line with the resource-based view, to the extent that resources are valuable, rare, inimitable, non-substitutable and exploitable, resources determine the competitiveness of enterprises (Park \& Ryu 2015:340; Sok et al. 2015:2). Therefore, resources contribute to an enterprise's performance through its ability to contribute to innovativeness (Park \& Ryu 2015:339; Sok et al. 2015:18; Vicente et al. 2015:30).
Small, medium and micro-sized enterprises are most likely to have limited tangible resources compared to their larger counterparts (Ates \& Bititci 2011:5602; Park \& Ryu 2015:340). Because of this, SMMEs are urged to possess intangible resources as these can supply a much greater contribution towards competitive advantage (Park \& Ryu 2015:340). Intangible resources are embedded within the enterprise and are difficult to point out. These resources are, therefore, more difficult to imitate and because they contribute to overall innovative performance, they are valuable (Alegre, Sengupta \& Lapiedra 2011:464; Park \& Ryu 2015:340). In fact, Alegre et al. (2011:464), as well as Halme and Korpela (2014:547-548), have found that limited resources can be advantageous for innovation development. The authors attribute this to the different resource combinations that exist for the creation of innovative offerings. Therefore, the size of an enterprise has an insignificant bearing on the enterprise's innovation development. Park and Ryu (2015:341), Sok et al. (2015:17) and Vicente et al. (2015:42) conclude that innovation capabilities and their ability to bring competitive advantage should not be viewed in isolation. The authors further explain that resources are to be deployed in such a way that they strategically leverage an enterprise's capabilities and are complementary to those capabilities. Therefore, the ability to deploy a resource is more important than the actual resource. Innovation capabilities are peculiar attributes of enterprises, which should be linked to their dimensions and seen as a whole to explain an enterprise's competitiveness (Vicente et al. 2015:42). It is this characteristic of interdependence that dictates an enterprise's competitiveness (Park \& Ryu 2015:341). The dimensions of innovation capabilities are discussed in detail in the section 'Dimensions of innovation capabilities'.

\section{Dimensions of innovation capabilities}

Forsman's (2011) study identified dimensions as being reflective of the degree of innovation capability possessed by small and medium manufacturing and service enterprises. The items generated for Forsman's study were based on concepts introduced in previous studies that identified innovation typologies (Forsman 2011:739). The seven items generated are capabilities for knowledge exploitation, entrepreneurial capabilities, risk management capabilities, networking capabilities, development capabilities, change management capabilities, and market and customer knowledge capabilities (Forsman 2011:744; Forsman \& Rantanen 2011:35), which are discussed as follows.

\section{Knowledge exploitation}

Knowledge exploitation refers to the ability to be aware of external knowledge relevant to current practice, to internalise and assimilate this new knowledge and to exploit it for innovation purposes as needed (Alegre et al. 2011:457; Forsman \& Rantanen 2011:49). Knowledge exploitation was formed from the need for an enterprise's employees to assimilate information and knowledge from external association in R\&D (Forsman 2011:740; Kostopoulos et al. 2011:1336; Spithoven et al. 2011:11). This term was extended 
to include the ability to use capabilities to absorb innovation stimuli of technology and humans (Smith et al. 2011:10). Cohen and Levintha (in Forsman 2011:740; Forsman \& Rantanen 2011:32; Kostopoulos et al. 2011:1335; Lewin, Massini \& Peeters 2014:1346; Spithoven et al. 2011:12) conceptualise absorptive capacity as the ability of a firm to recognise the value of new, external information, assimilate it, and apply it to commercial ends'. It is further argued that absorptive capacity promotes the speed, frequency and magnitude of innovation (Kostopoulos et al. 2011:1336; Spithoven et al. 2011:12).

\section{Entrepreneurial capabilities}

Entrepreneurial capabilities describe the ability to be aware of new opportunities to seize the new opportunity for developing new solutions and to exploit opportunities for creating new profit (Forsman \& Rantanen 2011:49). In accordance with entrepreneurial capabilities and absorptive capacity, dynamic innovation capabilities consist of the ability to transform knowledge into a competitive advantage (Forsman 2009:503). Dynamic capabilities can be further disaggregated into the capacity to sense and shape opportunities and threats, to seize opportunities and to maintain competitiveness through the enhancement, combination, reconfiguration and protection of the enterprise's intangible and tangible resources (Forsman \& Rantanen 2011:32; Teece 2007:1319).

\section{Risk management capabilities}

Risk management capabilities describe the ability to assess risk, being willing to take risk and the actual ability to take risk (Forsman \& Rantanen 2011:49). Smaller enterprises are often more agile than their larger counterparts; however, they are also highly vulnerable to major shocks stemming from the external environment (Forsman \& Rantanen 2011:29; Smit \& Watkins 2012:6324). It is imperative that SMMEs make risk management a priority if they are to identify and buffer against risk and be better equipped to utilise their existing resources in times of uncertainty to ensure survival (Smit \& Watkins 2012:6324).

\section{Networking capabilities}

Networking capabilities refer to whether or not the enterprise adopts a networking orientation, and whether the enterprise is able to create collaborative relationships and exploit the networks in the existing enterprise (Forsman 2011:740; Forsman \& Rantanen 2011:49). The social capital network of an enterprise refers to the macro-components of the enterprise, such as its suppliers, competitors and agents, which directly and indirectly provide the enterprise with knowledge for innovation (Cantner et al. 2010:1940). Smith et al.'s (2011:23) conceptualisation of social capital network concurs with that of Cantner et al. (2010:1940), and it is described as embedded knowledge from interactions amongst individuals through their networks of interrelationships. These social relationships are considered an asset for organisations and can be 'banked, analogously to financial capital' (Toth 2006:514). For an organisation to be conducive to emerging relationships, it should contain the following dimensions (Hazelton \& Keenan in Toth 2006:514):

- A system of networks that impact on relationship outcomes

- People have opportunities to send and receive information and have knowledge of the correct communication channels

- The timing is appropriate

- Referral is allowed and encouraged

- It has appropriate social organisation.

Social capital is beneficial when the society is diverse because enterprises learn from each other and collaborate and assist each other in the achievement of goals (Martínez-Fernández \& Molina-Morales 2010:261). Social capital in the form of cross-industry collaboration is based on the approach of analogical thinking, where the transfer of applications and technology takes place from one industry to another (Enkel \& Heil 2014:243). An important factor to note in social capital is geography because proximity intensifies the exchange of knowledge (Cantner et al. 2010:1940). Furthermore, cognitive distance affects the perception and interpretation of knowledge, which influences collaboration between social networks; therefore, high cognitive distance results in exploratory innovation (Enkel \& Heil 2014:244). Exploratory innovation is a radical innovation developed from the necessary synthesis of new knowledge and the enterprise's existing knowledge base to create an offering that is, essentially, a new product (Enkel \& Heil 2014:242).

The benefits of networking are categorised into two classes, namely, tangible and intangible benefits (Forsman 2011:740). Improved returns and market share, along with competitive advantage, are some of the tangible benefits of social networking, whereas the formations of capabilities are the intangible benefits of social networking (Forsman 2011:740). Social capital networks help SMMEs access the market and resources lacking in the enterprise because of its size and age (Ates \& Bititci 2011:5602; Jørgensen \& Ulhøi 2010:397; Park \& Ryu 2015:340). Networks are a means of gaining knowledge for sustainable innovation because knowledge sharing enhances an enterprise's innovation capacity (Jørgensen \& Ulhøi 2010:397).

\section{Development capabilities}

Development capabilities refer to the ability to create new innovations that are different from what the competition is offering customers, being able to improve on existing products and services offered by the enterprise and being able to exploit the innovations that have been developed by others (Forsman \& Rantanen 2011:49). Forsman (2009:502) and Forsman and Rantanen (2011:30) state that innovations have been studied as a typology that makes the distinction between incremental and radical innovation. The authors go on to describe incremental innovation as the enhancement of the existing processes, making operations more effective and improving quality or reducing cost. On the other hand, radical innovations are characterised as discontinuations in technology and the market. This typology can be further 
analysed based on market-driven innovations and drivingmarket innovation (Zortea-Johnston, Darroch \& Matear 2012:146). The authors exemplify market-driven innovations as being customer-focused and unlikely to produce radical ideas. Because customers often perceive their needs from a frame of the known and familiar, it limits their ability to thoroughly articulate their needs and wants. Conversely, the authors describe driving-market innovations as those innovations that create new customers, redefine the market, lead existing customers and meet the concealed needs and wants of customers. Enterprises that adopt a market-driven innovation orientation, as opposed to a driving-market innovation orientation, are likely to strain their competitive advantage and, therefore, their long-term survival because of their inability to create radical change in the market (Zortea-Johnston et al. 2012:146). Small, medium and microsized enterprises are said to be more flexible than their larger counterparts and should, as a result, be able to adapt and conform to the market more easily (Smit \& Watkins 2012:6324). According to Shahbazi, Eraditifam and Heydarabadi (2018:3), there is a direct connection between organisational flexibility and competitiveness. Flexibility adds to competitive advantage and is therefore essential for the growth of SMMEs.

\section{Change management capabilities and market and customer knowledge capabilities}

Change management capabilities, which also include market and customer knowledge capabilities, are the abilities to implement change quickly. Market and customer knowledge is the capability to acquire new customers, expand into new markets and increase sales to current customers (Forsman \& Rantanen 2011:49). According to Ates et al. (2013:47), as well as Ates and Bititci (2011:5614), internal and external change initiatives should be implemented with careful consideration given to planning and communication. The authors explain that in implementing critical change steps, owner-managers tend to neglect the soft aspects of change, such as culture, leadership and vision. The authors advise that SMMEs should adopt a strategic and long-term perspective of change, as opposed to treating change as the management of a project that is short-term and more operational in nature. In addition, owner-managers are urged to proactively manage change and not wait for external features in the environment, such as customer complaints, to impose the changes.

\section{Research methodology}

The purpose of the study is to explore the innovation capacity of small, medium and large-sized South African consulting engineering firms. Basic (pure) research is undertaken with the primary objective of producing new knowledge and understanding specific phenomenon. This study is basic in nature as it is undertaken to produce new knowledge and understanding of the degree of innovation capacity present in South African consulting engineering firms. This is achieved by observing and measuring the innovation capabilities of South African consulting engineering firms as is, without manipulating these variables. These capabilities are, namely, knowledge exploitation, entrepreneurial capabilities, risk management capabilities, networking capabilities, development capabilities, change management capabilities, and market and customer capabilities. Through the observation and measurement of the capabilities, the degree of innovation capacity has been gauged. This research is non-experimental (ex post facto) because of its quantitative descriptive status, which compels the researcher to simply observe and measure without intervening and manipulating variables to test the causeeffect relationships. This cross-sectional study created a snapshot of the reality of innovation capacity at the point in time when the survey was conducted. Therefore, the study does not intend to examine changes in the degree of innovation capacity over time as a longitudinal study would.

The study was conducted in field conditions; no artificial environments were created for the study. Participants' completed questionnaires that generated raw, unanalysed quantitative data. The researcher collected this primary data and analysed it to deduce the degree of innovation capacity of small, medium and large-sized South African consulting engineering firms.

The rationale for using a quantitative research approach is based, predominantly, on other leading researchers having used a similar approach. Forsman and Rantenan (2011:27) used a quantitative research approach to explore the differences in innovation capacity and the diversity of developed innovations across four enterprise categories within small manufacturing and service enterprises. Forsman (2011:739) used the same quantitative approach to explore the kinds of innovations developed in small manufacturing and service enterprises and to explore the degree of innovation capacity of those small enterprises.

\section{Sampling design}

The target population for the study was consulting engineering firms operating in South Africa. Consulting Engineers South Africa defines SMEs based on only the total annual turnover. Consulting Engineers South Africa's definition of SMEs has been adopted for the purpose of this study (CESA 2017):

- A small consulting engineering firm has an annual turnover equal to or less than $\mathrm{R} 11.5 \mathrm{~m}$.

- A medium consulting engineering firm's annual turnover exceeds R11.5m but not R35m.

- A large consulting engineering firm's annual turnover exceeds R35m.

The study made use of a probability sampling method because every participant had a known and equal chance of being included in the sample. In order to provide adequate data for uncovering and analysing differences in the innovation capabilities of the sub-populations or 
strata - namely small, medium and large-sized consulting engineering firms - a comparison of these two categories of firms was required (Cooper \& Schindler 2014:351). Stratified random sampling was used as the probability sampling method to increase the sample's statistical efficiency and to provide adequate data for analysing the two strata (Cooper \& Schindler 2014:351).

\section{Ethical consideration}

Ethical approval to conduct the study was obtained from the University of Pretoria (ethical clearance number: EMS041/71).

\section{Results and findings Univariate descriptive statistics}

\section{Composite score for innovation capacity}

Composite scores were calculated for overall innovation capacity by calculating the average scores of innovation capabilities, which are sub-dimensions of innovation capacity (Table 1). The results indicate that innovation capacity scored a mean of 3.655 on a five-point rating scale of innovation capabilities. This value lies between 'average' and 'high'. Individual composite scores were calculated for individual

TABLE 1: Innovation capacity and sub-dimension composite scores.

\begin{tabular}{|c|c|c|c|c|}
\hline$\overline{\text { Capability }}$ & Size of firm & $N$ & Mean & SD \\
\hline \multirow[t]{4}{*}{ Innovation capacity } & Total & 94 & 3.655 & 0.599 \\
\hline & Small & 29 & 3.499 & 0.638 \\
\hline & Medium & 40 & 3.707 & 0.536 \\
\hline & Large & 25 & 3.752 & 0.614 \\
\hline \multirow{4}{*}{$\begin{array}{l}\text { Capabilities for knowledge } \\
\text { exploitation }\end{array}$} & Total & 94 & 3.713 & 0.621 \\
\hline & Small & 29 & 3.575 & 0.745 \\
\hline & Medium & 40 & 3.767 & 0.519 \\
\hline & Large & 25 & 3.787 & 0.615 \\
\hline \multirow[t]{4}{*}{ Entrepreneurial capabilities } & Total & 94 & 3.731 & 0.579 \\
\hline & Small & 29 & 3.540 & 0.523 \\
\hline & Medium & 40 & 3.808 & 0.584 \\
\hline & Large & 25 & 3.827 & 0.602 \\
\hline \multirow[t]{4}{*}{ Risk management capabilities } & Total & 94 & 3.578 & 0.579 \\
\hline & Small & 29 & 3.368 & 0.686 \\
\hline & Medium & 40 & 3.617 & 0.515 \\
\hline & Large & 25 & 3.760 & 0.476 \\
\hline \multirow[t]{4}{*}{ Networking capabilities } & Total & 94 & 3.759 & 0.658 \\
\hline & Small & 29 & 3.667 & 0.787 \\
\hline & Medium & 40 & 3.758 & 0.528 \\
\hline & Large & 25 & 3.867 & 0.694 \\
\hline \multirow[t]{4}{*}{ Development capabilities } & Total & 94 & 3.564 & 0.515 \\
\hline & Small & 29 & 3.471 & 0.508 \\
\hline & Medium & 40 & 3.617 & 0.410 \\
\hline & Large & 25 & 3.587 & 0.662 \\
\hline \multirow{4}{*}{$\begin{array}{l}\text { Change management } \\
\text { capabilities }\end{array}$} & Total & 94 & 3.681 & 0.707 \\
\hline & Small & 29 & 3.552 & 0.632 \\
\hline & Medium & 40 & 3.750 & 0.707 \\
\hline & Large & 25 & 3.720 & 0.792 \\
\hline \multirow{4}{*}{$\begin{array}{l}\text { Market and customer } \\
\text { knowledge capabilities }\end{array}$} & Total & 94 & 3.560 & 0.534 \\
\hline & Small & 29 & 3.322 & 0.587 \\
\hline & Medium & 40 & 3.633 & 0.488 \\
\hline & Large & 25 & 3.720 & 0.458 \\
\hline
\end{tabular}

SD, standard deviation. innovation capabilities. The results further indicate that innovation capacity scored a mean of 3.499, 3.707 and 3.752 for small, medium and large firms, respectively. Large firms have the highest innovation capacity, whereas small-sized firms have the lowest capacity. The capability that scored highest amongst the respondents is networking capabilities $(M=3.759, \mathrm{SD}=0.658)$, and the capability that scored the lowest is market and customer knowledge $(M=3.560, \mathrm{SD}=0.534)$.

\section{Firmographic profile of respondents' enterprises}

A total of 94 responses were collected, of which $42.6 \%$ consisted of medium-sized firms which reported an annual turnover of 'Less than R35 million, but greater than R11.5 million'. The second-largest pool of respondents is small firms which reported an annual turnover of 'Equal to or less than R11.5 million', representing $30.9 \%$ of respondents. Large firms represented $26.6 \%$ of respondents and reported an annual turnover of 'Greater than R35 million'.

Furthermore, $86.2 \%$ of small firms has fewer than 20 employees, almost $50 \%$ of medium-sized firms has 5-19 employees and $60 \%$ of large firms have more than 50 employees. The majority of all small, medium and large enterprises have been in operation for more than 10 years, almost $40 \%, 45 \%$ and $80 \%$, respectively. The respondents indicated that most of their operations are in civil engineering for small, medium and large-sized firms, as the respondents reported $51 \%, 37 \%$ and $27 \%$, respectively. The results show that small, medium and large-sized firms operate mostly in the Gauteng province, as the respondents reported $40 \%, 43 \%$ and $40 \%$, respectively. Responses show larger firms across the country, even operating outside South Africa, whereas smaller firms were not represented in each province.

\section{Demographic profile of respondents}

The respondents comprised $92.5 \%$ men and $7.5 \%$ women. The share of respondents aged 'up to 45 years old' (36.6\%) is the same share of respondents who were between the ages of ' 46 and 55'. The rest of the respondents reported being '+56 years old', which represented $26.9 \%$ of the responses. The education levels of respondents indicate that 'post-graduate degrees' (39.8\%) have the highest incidence. 'Bachelor's degrees' have the second highest incidence with $38.7 \%$ and 'Up to diploma' has the lowest incidence amongst respondents (21.5\%).

TABLE 2: Chi-square test for association between external input and size of firm.

\begin{tabular}{lcccc}
\hline Investment in R\&D & Small firm & Medium firm & Large firm & $\begin{array}{c}\text { Total } \\
\text { respondents }\end{array}$ \\
\hline No R\&D & 9 & 8 & 4 & 21 \\
Less than R20 000 & 8 & 6 & 1 & 15 \\
R20 001 - R50 000 & 7 & 17 & 6 & 30 \\
R50 001 - R100 000 & 2 & 6 & 4 & 12 \\
R100 001 or more & 3 & 3 & 10 & 16 \\
\hline Total & $\mathbf{2 9}$ & $\mathbf{4 0}$ & $\mathbf{2 5}$ & $\mathbf{9 4}$ \\
\hline
\end{tabular}

$R \& D$, research and development. 
TABLE 3: Spearman's correlation coefficient innovation capabilities and external input.

\begin{tabular}{|c|c|c|}
\hline Innovation capability & Variable & External input \\
\hline \multirow[t]{3}{*}{ Investment in R\&D } & Correlation coefficient & 0.134 \\
\hline & Sig. (two tailed) & 0.198 \\
\hline & $N$ & 94 \\
\hline \multirow{3}{*}{$\begin{array}{l}\text { Capabilities for knowledge } \\
\text { exploitation }\end{array}$} & Correlation coefficient & $0.298 * *$ \\
\hline & Sig. (two tailed) & 0.004 \\
\hline & $N$ & 94 \\
\hline \multirow[t]{3}{*}{ Entrepreneurial capabilities } & Correlation coefficient & $0.215^{*}$ \\
\hline & Sig. (two tailed) & 0.038 \\
\hline & $N$ & 94 \\
\hline \multirow[t]{3}{*}{ Risk management capabilities } & Correlation coefficient & $0.338^{* *}$ \\
\hline & Sig. (two tailed) & 0.001 \\
\hline & $N$ & 94 \\
\hline \multirow[t]{3}{*}{ Networking capabilities } & Correlation coefficient & $0.283^{* *}$ \\
\hline & Sig. (two tailed) & 0.006 \\
\hline & $N$ & 94 \\
\hline \multirow[t]{3}{*}{ Development capabilities } & Correlation coefficient & $0.235^{*}$ \\
\hline & Sig. (two tailed) & 0.022 \\
\hline & $N$ & 94 \\
\hline \multirow{3}{*}{$\begin{array}{l}\text { Change management } \\
\text { capabilities }\end{array}$} & Correlation coefficient & $0.386^{* *}$ \\
\hline & Sig. (two tailed) & 0 \\
\hline & $N$ & 94 \\
\hline \multirow{3}{*}{$\begin{array}{l}\text { Market and customer } \\
\text { knowledge capabilities }\end{array}$} & Correlation coefficient & $0.406^{* *}$ \\
\hline & Sig. (two tailed) & 0 \\
\hline & $N$ & 94 \\
\hline \multirow{3}{*}{$\begin{array}{l}\text { External input through } \\
\text { networking }\end{array}$} & Correlation coefficient & 1 \\
\hline & Sig. (two tailed) & 0 \\
\hline & $N$ & 94 \\
\hline
\end{tabular}

R\&D, research and development; Sig, significant.

*, Correlation is significant at the 0.05 level (two tailed); **, correlation is significant at the 0.01 level (two tailed).

\section{Bivariate descriptive statistics}

\section{Chi-square test of independence for research and development and firm size}

The results of the chi-square test for independence (Table 2) show that the size of a firm is associated with the amount of R\&D the firm invests in itself $\left(\chi^{2}=20.483\right.$; $p=0.009)$.

\section{Spearman correlation between external input and innovation capabilities and research and development investment}

A medium-strength positive correlation was found between market and customer knowledge capability and external input $(r=0.46, p<0.01)$ (Table 3$)$. The other six capabilities showed only a mild correlation with external input.

\section{Non-parametric tests}

Investment in R\&D, entrepreneurial capabilities, risk management capabilities and market and customer knowledge capabilities were significantly affected by the firm size (Table 4). For these observed variables, the Jonckheere-Terpstra test revealed a significant trend in the data at a significance level of $0.05 \%$ : the larger the size of the firm, the higher the scoring on the specified capabilities.

The study results suggest that respondents' engineering consulting firms have an 'average' to 'high' innovation capacity; medium- $(M=3.707, \mathrm{SD}=0.536)$ and large-sized
TABLE 4: Kruskal-Wallis test and Jonckheere-Terpstra test for ordered alternatives. Investment in R\&D Significance

\begin{tabular}{lcc}
\cline { 2 - 3 } & Kruskal-Wallis test & $\begin{array}{c}\text { Jonckheere-Terpstra } \\
\text { test for ordered } \\
\text { alternatives }\end{array}$ \\
\hline Investment in R\&D & 0.004 & 0.001 \\
Knowledge exploitation & 0.177 & 0.103 \\
Entrepreneurial capabilities & 0.046 & 0.019 \\
Risk management capabilities & 0.044 & 0.012 \\
Networking capabilities & 0.609 & 0.316 \\
Development capabilities & 0.383 & 0.279 \\
Change management capabilities & 0.384 & 0.206 \\
Market and customer knowledge & 0.35 & 0.103 \\
capabilities & & 0.060 \\
External input through networking & 0.103 &
\end{tabular}

Note: Asymptotic significance is displayed. The significance level is 0.05 . $R \& D$, research and development.

firms $(M=3.752, \mathrm{SD}=0.614)$ have a similar capacity, but small firms $(M=3.499, \mathrm{SD}=0.638)$ are lagging. Results further indicate that there exists a significant difference in entrepreneurial capabilities, risk management capabilities and capabilities for market and customer knowledge: larger firms have a higher scoring than smaller firms. In particular, the results for risk management capabilities and capabilities for market and customer knowledge show small firms in the lower range of 'average' to 'high', medium firms just over the midpoint for 'average' to 'high' and large firms in the upper range of 'average' to 'high'. This finding prompts the need to explore why small consulting engineering firms are lagging in their innovation capabilities and, particularly, in their risk management capabilities and their capabilities for market and customer knowledge.

As mentioned, innovation capacity is the capability of an enterprise to progress its resources and capabilities to discover and take advantage of opportunities to better satisfy customer needs; thus, innovation capacity is driven by resources and different capabilities (Forsman 2011:740). This study observed small, medium and large firms' internal and external resources as R\&D and external input, respectively, to identify opportunities to improve the overall innovation capacity. The findings show that the size of the firm is associated with the amount of R\&D investment larger firms invested more financial assets into their R\&D efforts. Therefore, the larger the firm, the more R\&D investment they are likely to invest in the firm. However, there was no significant difference across firm size for external input. In addition, a significant moderate-strength positive correlation was found between external input and capabilities for market and customer knowledge. This suggests that there is an opportunity for smaller-sized firms to invest in external input and directly improve their capabilities for market and customer knowledge to bridge the gap in capability between itself and larger sized firms.

\section{Managerial implications}

The study suggests that there is room for improvement with regard to engineering consulting firms' innovation capacity, 
particularly with small and medium-sized firms. Capability building efforts of entrepreneurs, policymakers and associations or industry groups should prioritise capabilities that are lagging, namely, entrepreneurial capabilities, risk management capabilities and capabilities for market and customer knowledge. Special focus should be given to small firms with regard to risk management capabilities and the capabilities for market and customer knowledge. Smith et al. (2011:8) offer investments in human and technological capital as an approach to improving innovation capabilities. However, a more practical and, seemingly, equally effective approach is the former, given that small and medium-sized firms are often financially constrained and would, therefore, be unlikely to make significant strides in technological advancements. Investments in human capital come in the form of training and enhancing skills within the firm (Bernard et al. 2014:4). The latter, however, should not be completely dismissed, and technological investments should be evaluated on their own merit.

Given that investments in R\&D improve innovation capacity, it is suggested that policymakers invest in more financial assistance for small and medium firms which also support innovation (Forsman \& Rantanen 2011:41). Small and medium-sized firms often have limited financial resources and cite lack of finance as a primary reason for failure. If the institutions can provide an environment where SMEs are more likely to be innovative, then SMEs will be more likely to fulfil their developmental role in the economy (GEM 2014:4; Nieman \& Pretorius 2004:3; Olawale \& Garwe 2010:729). Furthermore, because the R\&D activities of SMMEs are often informal, it is of paramount importance that entrepreneurs are mindful of daily business developments and are constantly seeking opportunities to collaborate in their efforts to be a more innovative firm (Forsman 2011:740).

\section{Conclusion}

This study investigated the innovation capacity of consulting engineering firms operating in South Africa and identified the differences in innovation capabilities across these firms (i.e. small, medium and large-sized). Innovation capacity is an overall construct that generates capabilities for knowledge exploitation, entrepreneurial capabilities, risk management capabilities, networking capabilities, development capabilities, change management capabilities and market and customer knowledge capabilities (Forsman 2011:744; Forsman \& Rantanen 2011:35).

There remains minimal available literature exploring and measuring the innovation capacity and innovation capabilities of South African SMMEs, let alone consulting engineering firms operating in South Africa (Forsman 2011:739-750; Forsman \& Rantanen 2011:27-50; Gemünden \& Rohrbeck 2010). This study was conducted to enhance the body of knowledge, available to academics, on the topic of innovation development of consulting engineering firms operating in South Africa.

\section{Recommendations for future research}

This study adopted the precedent of Forsman (2011) and measured the internal, transformative and external inputs of innovation capacity as R\&D investment, innovation capabilities and external input. However, given the research objectives of the study, which were to measure the innovation capabilities of the consulting engineering firms and identify differences in capabilities across firm size, the study did not focus on internal and external input factors to innovation capacity. As such, the literature investigated was constrained primarily to understanding innovation capacity as an overall construct and to understanding the innovation capabilities.

The differences that were found, by this study, in innovation capabilities across firm size prompt the need for future research to explore why small consulting engineering firms are lagging in their innovation capabilities, and particularly in their risk management capabilities and their capabilities for market and customer knowledge.

Given that innovation capabilities provide a view on the transformative capabilities of the firms, future research should expand this view to include internal and external inputs to innovation capacity, even in the literature. Perhaps the differences in innovation capabilities across firm size can be explained by the internal and external inputs to innovation capacity, which the GII has alluded to as being critical to the innovation process.

\section{Acknowledgements Competing interests}

The authors declare that they have no financial or personal relationships that may have inappropriately influenced them in writing this research article.

\section{Authors' contributions}

M.M.M. contributed to the introduction, literature review, research methodology, results and findings, and conclusion; O.S. contributed to the introduction and literature review.

\section{Funding information}

This research received no specific grant from any funding agency in the public, commercial or not-for-profit sectors.

\section{Data availability}

The data that support the findings of this study are available from the corresponding author, O.S., upon reasonable request.

\section{Disclaimer}

The views and opinions expressed in this article are those of the authors and do not necessarily reflect the official policy or position of any affiliated agency of the authors. 


\section{References}

Alegre, J., Sengupta, K. \& Lapiedra, R., 2011, 'Knowledge management and innovation performance in a high-tech SMEs industry', International Small Business Journal 31(4), 454-470. https://doi.org/10.1177/0266242611417472

Ates, A. \& Bititci, U., 2011, 'Change process: A key enabler for building resilient SMEs', International Journal of Production Research 49(18), 5601-5618. https://doi.org/ 10.1080/00207543.2011.563825

Ates, A., Garengo, P., Cocca, P. \& Bititci, U., 2013, 'The development of SME managerial practice for effective performance management', Journal of Small Business and Enterprise Development 20(1), 28-54. https://doi.org/10.1108/14626001 and Enterprise

Bernard, A.L., Dutta, S., Reynoso, R.E. \& Wunsch-Vincent, S., 2014, The global innovation index 2014: The human factor in innovation, viewed 10 June 2015, from https:// index 2014: The human factor in innovation, viewed 10 June 2015, from
www.globalinnovationindex.org/userfiles/file/reportpdf/GII-2014-v5.pdf.

Cantner, U., Conti, E. \& Meder, A., 2010, 'Networks and innovation: The role of social assets in explaining firms' innovative capacity', European Planning Studies, 18(12) 1937-1956. https://doi.org/10.1080/09654313.2010.515795

Cape Argus, 2015, Ramaphosa states case for the government, viewed 07 July 2019 from https://reference-sabinet-co-za.uplib.idm.oclc.org/document/SAMARGUS 201509102_3408.

CESA, 2017, Become a CESA member, viewed 17 September 2017, from http://www. cesa.co.za/membership.

Chimucheka, T., 2013, 'Overview and performance of the SMMEs sector in South Africa', Mediterranean Journal of Social Sciences 4(14), 783-795.

Cooper, D.R. \& Schindler, P.S., 2014, Business research methods, McGraw-Hill, New York, NY.

Construction Industry Development Board, 2015, Construction monitor - Employment Quarter 3 - 2015. October 2015, viewed 17 June 2016, from http://cidb.org.za/ publications/Documents/Construction\%20Monitor\%20-\%200ctober\%202015.pdf.

Dutta, S., Lanvin, B. \& Wunsch-Vincent, S., 2016, The global innovation index 2016 Winning with global innovation, viewed 31 October 2017, from https://www. wipo.int/edocs/pubdocs/en/wipo_pub_gii_2016.pdf.

Dutta, S., Lanvin, B. \& Wunsch-Vincent, S., 2017, The global innovation index 2016 Innovation feeding the world, viewed 31 October 2017, from https://www.wipo. int/edocs/pubdocs/en/wipo_pub_gii_2017.pdf.

Dutta, S., Reynoso, R.E., Guadagno, F., Lanvin, B., Leon, L.R., Saxena, K. et al., 2018, Global innovation index 2018: Energizing the world with innovation, viewed 30 September 2018, from https://www.globalinnovationindex.org/gii-2018-report.

Enkel, E.L. \& Heil, S., 2014, 'Preparing for distant collaboration: Antecedents to potential', Technovation, 34(4), 242-260. https://doi.org/10.1016/j.technovation. 2014.01.010

Forsman, H., 2009, 'Balancing capability building for radical and incremental innovations', International Journal of Innovation Management 13(4), 501-520. innovations', International Journal of Innovation
https://doi.org/10.1142/S1363919609002492

Forsman, H., 2011, 'Innovation capacity and innovation development in small enterprises. A comparison between the manufacturing and service sectors', Research Policy 40(5), 739-750. https://doi.org/10.1016/j.respol.2011.02.003

Forsman, H. \& Rantanen, H., 2011, 'Small manufacturing and service enterprises as innovators: A comparison by size', European Journal of Innovation Management 14(1), 27-50. https://doi.org/10.1108/14601061111104689

GEM, 2014, 2015 GEM South African report, viewed 22 July 2015, from http://www. gemconsortium.org/country-profile/108.

GEM, 2018, GEM 2017/18 global report, viewed 30 September 2018, from https:// www.gemconsortium.org/report.

Gemünden, H.G. \& Rohrbeck, R., 2010, 'Corporate foresight: Its three roles in enhancing the innovation capacity of a firm', Technological Forecasting and Social Change 78(2), 231-243. https://doi.org/10.1016/j.techfore.2010.06.019

Halme, M. \& Korpela, M., 2014, 'Responsible innovation toward sustainable development in small and medium-sized enterprises: A resource perspective',
Business Strategy and the Environment 23(8), 547-566. https://doi.org/10.1016/j. techfore.2010.06.019

Jørgensen, F. \& Ulhøi, J.P., 2010, 'Enhancing innovation capacity in SMEs through early network relationships', Creativity and Innovation Management 19(4), 397-404. https://doi.org/10.1111/j.1467-8691.2010.00577.x

Kostopoulos, K., Papalexandris, A., Papachroni, M. \& Ioannou, G., 2011, 'Absorptive capacity, innovation, and financial performance', Journal of Business Research 64(1), 1335-1343. https://doi.org/10.1016/j.jbusres.2010.12.005

Kruger, S. \& Steyn, A.A., 2019, Enhancing technology transfer through entrepreneurial development: Practices from innovation spaces, viewed 09 October 2020, from https://www.researchgate.net/publication/340022583 Enhancing technology transfer through entrepreneurial development practices from innovation spaces/link/5e731e71299bf1571848cc482/download.
Lewin, A.Y., Massini, S. \& Peeters, C., 2014, 'Sources of variation in the efficiency of adopting management innovation: The role of absorptive capacity routines, organizational legitimacy', Organisation Studies 35(9), 1343-1371. https://doi. organizational legitimacy', Organ
org/10.1177/0170840614539311

Martínez-Fernández, M.T. \& Molina-Morales, F.X., 2010, 'Social networks: Efforts of social capital on firm innovation', Journal of Small Business Management 48(2), 258-279. https://doi.org/10.1111/j.1540-627X.2010.00294.x

Mhlanga, I., 2016, 'FM economic indicators', Financial Mail, 31 March-06 April, p. 45.

National Government of South Africa, 2020, Construction Education and Training Authority (CETA), viewed 09 October 2020, from https://nationalgovernment. co.za/units/view/209/construction-education-and-training-authority-ceta.

National Skills Authority (NSA), 2020, SETAs: What do SETAs do, viewed 09 October 2020, from https://www.nationalskillsauthority.org.za/roles-and-functions/ setas/.

Nieman, G. \& Pretorius, M., 2004, Managing growth: A guide for entrepreneurs, Juta, Cape Town.

Olawale, F. \& Garwe, D., 2010, 'Obstacles to the growth of new SMEs in South Africa: A principal component analysis approach', African Journal of Business Management 4(5), 729-738, viewed n.d., from https://academicjournals.org/ article/article1380715803_Olawale\%20and\%20Garwe.pdf.

Oura, M.M., Zilber, S.N. \& Lopes, E.L., 2015, 'Innovation capacity, international experience and export performance of SMEs in Brazil', International Business Review 25(4), 921-932. https://doi.org/10.1016/j.ibusrev.2015.12.002

Park, T. \& Ryu, D., 2015, 'Drivers of technology commercialization and performance in SMEs: The moderating effect of environmental dynamism', Management Decision 53(2), 338-353. https://doi.org/10.1108/MD-03-2014-0143

PWC, 2015, Highlighting trends in the South African construction industry, viewed 17 June 2016, from https://www.pwc.co.za/en/assets/pdf/sa-construction-2015. pdf.

Radas, S. \& Božić, L., 2009, 'The antecedents of SME innovativeness in an emerging transition economy', Technovation 29(6-7), 438-450. https://doi.org/10.1016/j. technovation.2008.12.002

Seibert, S.E., Kraimer, M.L. \& Liden, R.C., 2001, 'A social capital theory of career success', Academy of Management Journal 2(44), 219-237. https://doi. org/10.2307/3069452

Services SETA, 2020, What we do, viewed 09 October 2020, from https://www. servicesseta.org.za/page?\&site=What_we_do.

Shahbazi, A., Eradatifam, M. \& Heydarabadi, S., 2018, The impact of two information technology resources on organizational agility and competitive advantage viewed 10 September 2020, from https://www.researchgate.net/ publication/329150946_The_impact_of_two_information_technology_ resources_on_organizational_agility_and_competitive_advantage.

Smit, Y. \& Watkins, J.A., 2012, 'A literature review of small and medium enterprises (SME) risk management practices in South Africa', African Journal of Business Management 6(21), 6324-6330. http://doi.org/10.5897/AJBM11.2709

Smith, A., Courvisanos, J., Tuck, J. \& McEachern, S., 2011, Building innovation capacity: The role of human capital formation in enterprises $-A$ review of the literature, viewed 31 March 2015, from https://library.bsl.org.au/jspui/bitstream/1/2752/1/ Fostering\%20enterprise.pdf\#page $=105$

Sok, P., O'Cass, A. \& Miles, M.P., 2015, 'The performance advantages for SMEs of product innovation and marketing resource-capability complementarity in emerging economies', Journal of Small Business Management 54(3), 1-22. http:// doi.org/10.1111/jsbm.12172

Spithoven, A., Clarysse, B. \& Knockaert, M., 2011, 'Building absorptive capacity to organise inbound open innovation in traditional industries', Technovation 30(2), 10-21. https://doi.org/10.1016/j.technovation.2009.08.004

Statistics South Africa, 2016, Finding a home in a big pond, viewed 17 June 2016, from http://www.statssa.gov.za/?p=6367.

Teece, D.J., 2007, 'Explicating dynamic capabilities: The nature and microfoundations of (sustainable) enterprise performance', Strategic Management Journal 28(13), 1319-1350. https://doi.org/10.1002/smj.640

Toth, E.L., 2006. 'Building public affairs theory', in C.H. Botan \& V. Hazleton (eds.), Public relations theory II, Lawrence Erlbaum Associates, Mahwah, NJ.

Vicente, M., Abrantes, J.L. \& Teixeira, M.S., 2015, 'Measuring innovation capability in exporting firms: The INNOVSCALE', International Marketing Review 32(1), $29-51$.

Willemse, J., 2010, SME failure statistics, viewed 14 July 2015, from https://www. theforumsa.co.za/forums/showthread.php/7808-SME-Failure-Statistics.

Zortea-Johnston, E., Darroch, J. \& Matear, S., 2012, 'Business orientations and innovation in small and medium-sized enterprises', International Entrepreneurship Management Journal 8(2), 145-116. http://doi.org/10.1007/s11365-0110170-7 